\title{
Local heat transfer in a rotating serpentine passage with rib-roughened surfaces
}

\author{
SHIN FANN, WEN-JEI YANG and NENGLI ZHANG \\ Department of Mechanical Engineering and Applied Mechanics, University of Michigan, Ann Arbor, \\ MI 48109, U.S.A.
}

(Received 8 December 1992 and in final form 13 July 1993)

\begin{abstract}
An experimental study is conducted on heat transfer in a rotating serpentine passage with ribroughened walls under uniform wall heat flux. Seven roughness configurations are tested to determine their effects on convective heat transfer enhancement. Results are obtained for heat transfer distributions which are compared with those having smooth surfaces. It is revealed that rotation, roughness and the angle-ofattack of ribs have significant influences on the heat transfer performance with 45PR having the best enhancement in both stationary and rotating cases. The flow mechanism in a rib-roughened passage is proposed to explain its effect on heat transfer performance.
\end{abstract}

\section{INTRODUCTION}

THE DEMAND for increasing thermal efficiency in turbomachinery and other rotary systems has promoted a great effort in the development of efficient techniques for cooling turbine blades. Recently, multi-pass channels, so-called serpentine passages, have been studied for their excellent heat transfer performance. Hajek and Higgins [1] reported the first experimental study on this topic. It was disclosed that the minimum level of heat transfer can be predicted accurately by Kays' laminar flat plate correlation [2], and that the centripetal buoyancy limits the laminarization process. For $R e=25000$ and $R a>10^{11}$, the leading side shear layer was found to become transitional while heat transfer increased. Clifford [3] studied a rotating multipass model with trip normal to the flow using transient measurement techniques. He observed increases in heat transfer of $36 \%$ on the trailing side and decreases of $24 \%$ on the leading side of the first passage. Experiments were performed by Wagner et al. [4] to determine the effects of buoyancy and Coriolis forces on heat transfer. Local heat transfer coefficients were found to decrease by as much as $60 \%$ and increase by $250 \%$ from no rotation levels. It was also disclosed that: (i) density ratio and Rossby number cause large changes in heat transfer for radially outward flow and relatively small changes for radially inward flow; (ii) the heat transfer ratio is primarily a function of a buoyancy parameter on the leading surface, regardless of flow direction; (iii) the heat transfer ratio on the trailing side is significantly affected by flow direction. The buoyancy parameter plays a strong role in radially outward flow and a relatively weak role in the radially inward flow near the trailing sides; and (iv) increasing density ratio generally increases heat transfer. However, the increase in heat transfer on the inward flowing passage is considerably less than that for outward flow.
Wagner et al. [5] and Johnson et al. [6] studied heat transfer in serpentine passages with roughness. The ribs were aligned perpendicular to the throughflow direction and on the trailing and leading walls. It was revealed that the heat transfer coefficients, where heat transfer increases with rotation, vary by as much as a factor of four due to rotation and buoyancy. The maximum value of the heat transfer coefficients with high rotation are only slightly higher than the highest level for the smooth wall model. Both the Coriolis and buoyancy effects must be considered in turbine blade cooling designs with ribs, and the effects of rotation were pronoucedly different depending upon the flow direction. Johnson et al. [6] concluded that the heat transfer with 45 degree angle-of-attack is less sensitive to buoyancy than heat transfer in models with either smooth walls or normal ribs. The entrance region heat transfer performance in a rotating four-pass serpentine flow passage with uniform wall heat flux was studied by Yang et al. [7]. The experiment was carried out without extension arm, and the passage walls were smooth. It was disclosed that the local heat transfer performance due to an increase in the rotational Rayleigh number is most prominent near the entrance but diminishes downstream. Mochizuki et al. [8] studied the heat transfer characteristics of a three-pass serpentine passage with rotation. Three-dimensional flow structure was disclosed to cause the heat transfer rate at the turns to be substantially higher than that at straight passages. This mechanism was observed by a flow visualization experiment for stationary conditions. At low Reynolds numbers, the local heat transfer performance was found to be primarily a function of buoyancy-forces. At higher Reynolds numbers, however, the circumferentially-averaged Nusselt number is only a weak function of the rotational Rayleigh and Rossby numbers. Dawes [9] described the application of a solution-adaptive, three-dimensional Navier-Stokes solver to the 


\section{NOMENCLATURE}

\begin{tabular}{|c|c|}
\hline$C_{\mathrm{p}}$ & specific heat $\left[\mathrm{kJ} \mathrm{kg}^{-1} \mathrm{C}{ }^{\prime}\right]$ \\
\hline$D_{\mathrm{h}}$ & $\begin{array}{l}\text { hydraulic diameter of channel in test } \\
\text { section }[\mathrm{m}]\end{array}$ \\
\hline$G$ & air mass flow rate $\left[\mathrm{kg} \mathrm{s}^{-1}\right]$ \\
\hline$h$ & $\begin{array}{l}\text { convective heat transfer coefficient } \\
{\left[\mathrm{W} \mathrm{m}^{-2} \mathrm{C}^{-1}\right]}\end{array}$ \\
\hline$k$ & $\begin{array}{l}\text { thermal conductivity of fluid } \\
{\left[\mathrm{W} \mathrm{m}^{-1} \mathrm{C}^{-1}\right]}\end{array}$ \\
\hline$N u(x)$ & local Nusselt number, see equation (2) \\
\hline$N u_{\mathrm{s}}$ & $\begin{array}{l}\text { local Nusselt number in passage with } \\
\text { smooth walls }\end{array}$ \\
\hline$N u_{\mathrm{x}}$ & local Nusselt number over a wall, $h D_{\mathrm{h}} / k$ \\
\hline$N u_{\infty}$ & Nusselt number for fully developed flow \\
\hline $\operatorname{Pr}$ & Prandtl number, $v / \alpha$ \\
\hline$q_{\mathrm{w}}$ & local wall heat flux $\left[\mathrm{W} \mathrm{m}^{-2}\right]$ \\
\hline $\operatorname{Re}$ & Reynolds number, $U_{0} D_{\mathrm{h}} / v$ \\
\hline Ro & Rossby number, $\Omega D_{\mathrm{h}} / U_{0}$ \\
\hline$T$ & temperature $[\mathrm{C}]$ \\
\hline$T a$ & $\begin{array}{l}\text { Taylor number, } \Omega D_{\mathrm{h}}^{2} / v=\operatorname{Re} R o \\
\text { temperature of air flow }[\mathrm{C}]\end{array}$ \\
\hline
\end{tabular}

$T_{h} \quad$ local bulk mean temperature ["C]

$T_{0} \quad$ inlet mean temperature [ $\mathrm{C}$ ]

$T_{\mathrm{w}} \quad$ wall temperature [ $\mathrm{C}$ ]

$U_{0} \quad$ inlet mean velocity $\left[\mathrm{m} \mathrm{s}^{-1}\right]$

$X \quad$ distance in the axial direction measured from flow inlet $[\mathrm{m}]$.

Greek symbols

\begin{tabular}{|c|c|}
\hline$\chi$ & thermal diffusivity of fluid, $k / \rho C$ \\
\hline$v$ & kinematic viscosity $\left[\mathrm{m}^{2} \mathrm{~s}{ }^{1}\right]$ \\
\hline$\rho$ & fluid density $\left[\mathrm{kg} \mathrm{m}^{-3}\right]$ \\
\hline & angular velocity of rotat \\
\hline
\end{tabular}

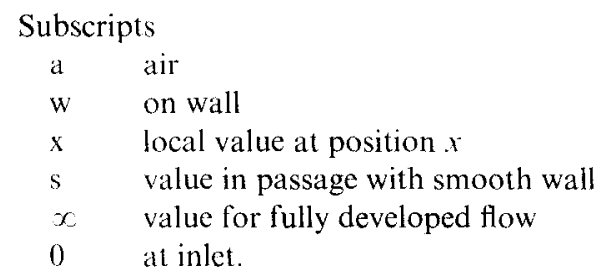

problem of the flow in turbine internal coolant passages.

In addition to the studies on rotating single- and multi-pass channels, several experimental studies in stationary channels were also reported. Heat transfer experiments in serpentine passages with skewed strips were conducted in a stationary model by Boyle [10]. Han [11] and Han et al. [12] studied heat transfer and friction in rectangular channels with turbulence promoters. Chandra et al. [13] examined the effects of rib angle on heat and mass transfer in a two-pass channel. Following the preceding works, Han and Zhang [14], Han et al. [15] and Han and Zhang [16] conducted a series of experiments to investigate the distributions and angle-of-attack of ribs on local mass transfer distributions in single- and three-pass channels. Abuaf and Kercher [17] investigated the heat transfer performance of turbine blades by a three-pass turbulated cooling passage in a $10 \mathrm{X}$ plexiglas test model. Heat transfer and fluid flow in a 180 deg sharp turn were also studied by Han et al. [15] and Choi et al. [18].

The present study investigates turbulent heat transfer in rotating three-pass (serpentine) passages with rib-roughened walls. Uniform wall heat flux was imposed on the passage walls. The effects of rotation, flow rate, ribs and angle-of-attack of ribs on heat transfer are examined. Results of local heat transfer coefficient distributions are presented.

\section{EXPERIMENTAL APPARATUS AND PROCEDURE}

The experimental apparatus consisted of a test section, a DC motor with controller, a heat source, an air supply system with an air filter, a flowmeter, and a high speed rotating joint and two slip rings used for power supply and a data acquisition system, as shown in Fig. 1. The cooling air from an air supply passed through an air filter, a flowmeter, and a high rotating joint. The flow then entered one end of the hollow shaft, turned into the serpentine passage and finally exited through the other end of the shaft. Electrical power was supplied to the film heaters by a variable current power source through a slip ring. A current meter and a voltmeter were used to measure the power. The entire rotating portion of the system was enclosed by a protective metal cover for safety.

The test section was comprised of a four-pass serpentine flow channel with a $2.54 \times 2.54 \mathrm{~cm}$ square cross section. Only the leading and trailing walls of the channel were heated with a thin-film, $0.025 \mathrm{~mm}$, stainless steel sheet. For the rib-roughened tests, brass

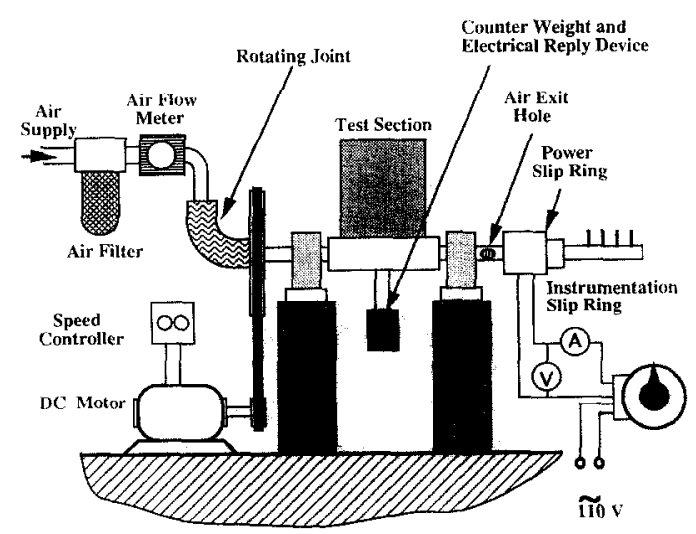

Fig. 1. Experimental apparatus. 
ribs with $0.2 \times 0.2 \mathrm{~cm}$ square cross section were glued onto the film and electrically insulated. The rib heightto-hydraulic diameter ratio, $e / D_{\mathrm{h}}$, is 0.0787 . Starting from the third rib, the wall temperature distributions were measured after every other rib by means of four well-distributed thermocouples between two ribs, as shown in Fig. 2. The wall temperature changes in the turns were also measured. The experimental results from Han et al. [15] and Yang et al. [7] indicated that the local heat transfer coefficients on the smooth and normal ribbed (aligned perpendicular to the flow direction) walls are fairly uniform in the lateral direction. Therefore, it is sufficient to measure only the local wall temperatures along the centerline of the channel, as in the present study. The installation of thermocouples was similar to those of Yang et al. [7] and Zhang et al. [19], and only the trailing and leading walls were fitted with E-type thermocouples.

The ribs were located on both the trailing and leading walls correspondingly positioned. The center of the first rib was placed $4.24 \mathrm{~cm}$ from the inlet of the test section. Other ribs were placed consistently along the streamwise centerline of the passage at a distance of $s / e=11$ until the end of the third straight passage. No heater foil was placed on the side walls with the whole piece of the test section being carefully insulated to minimize heat losses. In addition to the normal rib (a rib aligned perpendicular to the flow direction), Fig. 3 also illustrates seven different rib alignments (with an angle-of-attack of $45^{\circ}$ or $60^{\circ}$ ) adopted in the study to investigate the influence of angle-of-attack on heat transfer. Table 1(a) gives the notation which is used in the figures of results.

A constant wall heat flux experiment was selected for the present study because of its simplicity in construction and ease in operation. This is especially true

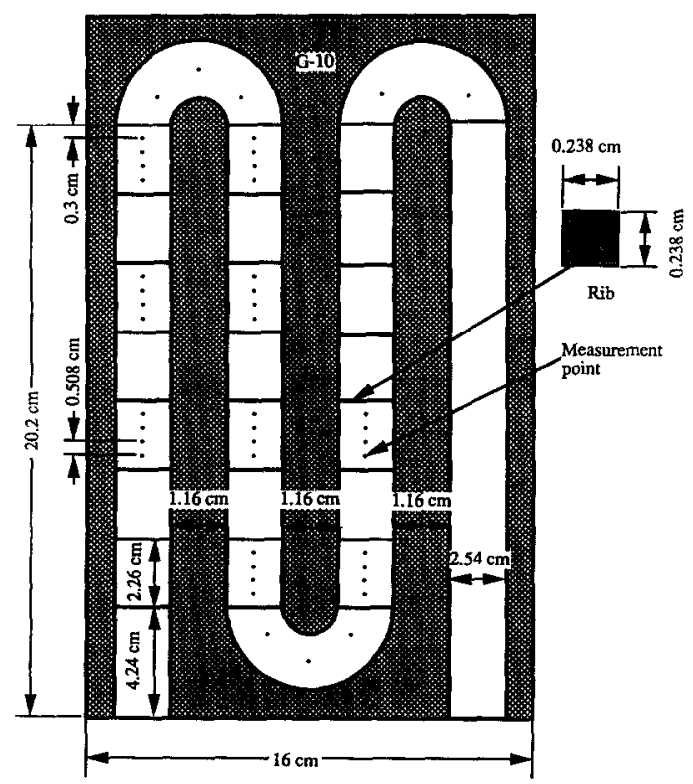

FIG. 2. Positions of ribs and thermocouples.

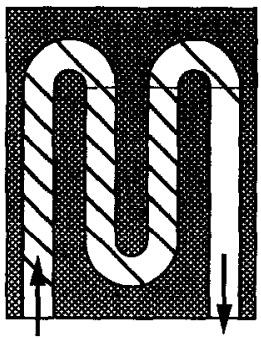

(a)

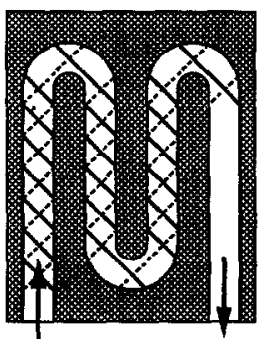

(c)

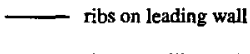

-....... ribs on trailing wall

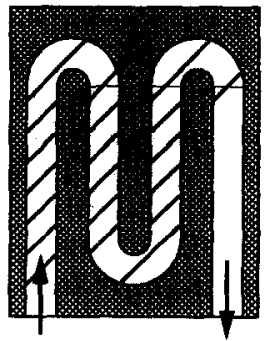

(b)

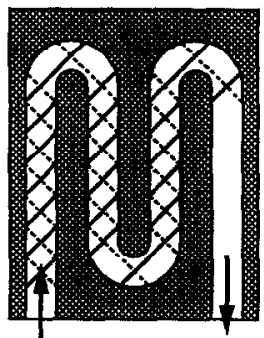

(d)

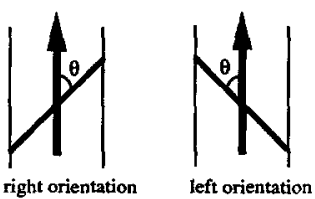

FIG. 3. Rib alignments: parallel (a) left orientation and (b) right orientation, and cross (c) right orientation and (d) left orientation (based on the orientation of ribs on the trailing wall).

for the investigation of the effect of ribs on local heat transfer coefficients. It should be noted that real turbine blades operate under a condition between the constant wall heat flux and constant wall temperature cases. First, tests were performed on a stationary channel at three different Reynolds numbers : 10240 ,

Table 1. (a) Configurations of ribs on channel walls and (b) range of parameters in experimental study

\begin{tabular}{clc}
\hline Case & Description in the text & Notation in figures \\
\hline 1 & 90 deg rib & $90 \mathrm{P}$ \\
2 & 60 deg parallel rib (right) & $60 \mathrm{PR}$ \\
3 & 60 deg parallel rib (left) & $60 \mathrm{PL}$ \\
4 & 60 deg cross rib (right) & $60 \mathrm{CR}$ \\
5 & 60 deg cross rib (left) & $60 \mathrm{CL}$ \\
6 & 45 deg parallel rib (right) & $45 \mathrm{PR}$ \\
7 & 45 deg parallel rib (left) & $45 \mathrm{PL}$ \\
\hline
\end{tabular}

(a)

\begin{tabular}{rccc}
\hline & \multicolumn{3}{c}{$R e$} \\
\hline r.p.m. & $R o-10240$ & 20650 & 31300 \\
\hline 16 & 0 & 0 & 0 \\
184 & 0.0485 & 0.0241 & 0.0159 \\
332 & 0.0770 & 0.0382 & 0.0252 \\
& 0.1389 & 0.0689 & 0.0455 \\
\hline
\end{tabular}

(b) 
20650 and 31300 . This was followed by experiments on the rotating test rig. The ranges of parameters in experimental study are listed in Table 1(b). For each Reynolds number, the test section was rotated at three different speeds: 116, 184 and 332 r.p.m. In each test, data acquisition was initiated $45 \mathrm{~min}$ after the test rig was started in order to assure that the system had reached a steady state.

\section{DATA REDUCTION}

Two methods were employed to calculate the energy supplied to the cooling air [7] : (1) (total energy sup- plied) - (heat losses) and (2) measured air inlet and outlet temperatures. Heat losses were measured for steady-state rotational conditions without throughflow. The temperature at a strategic position (the trailing wall at the first turn, i.e. $X / D_{\mathrm{h}}=8.86$ ) was maintained at the same temperature as in the corresponding throughflow case. The resulting calculated heat loss showed that both methods for calculating the energy supplied to the air obtained the same results within a variation of $5 \%$ [7]. The following equations were used to reduce the data :

$$
h(x)=q_{\mathrm{w}} / \Delta T(X)=q_{\mathrm{w}} /\left(T_{\mathrm{w}}(X)-T_{\mathrm{a}}(X)\right)
$$

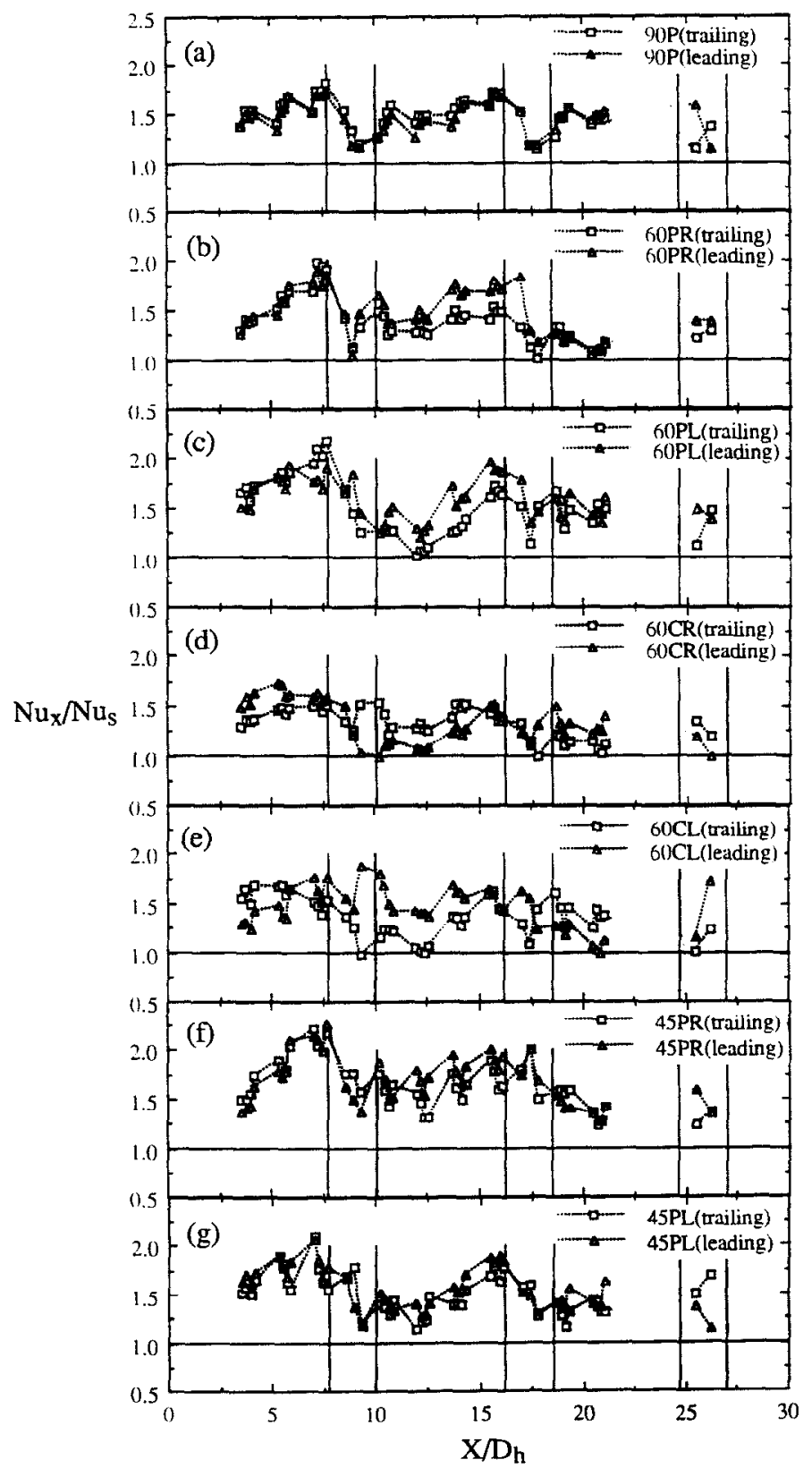

Fig. 4. Ratio of local Nusselt number of roughened passage to that of smooth passage at $R e=20650$ and $R o=0$. 


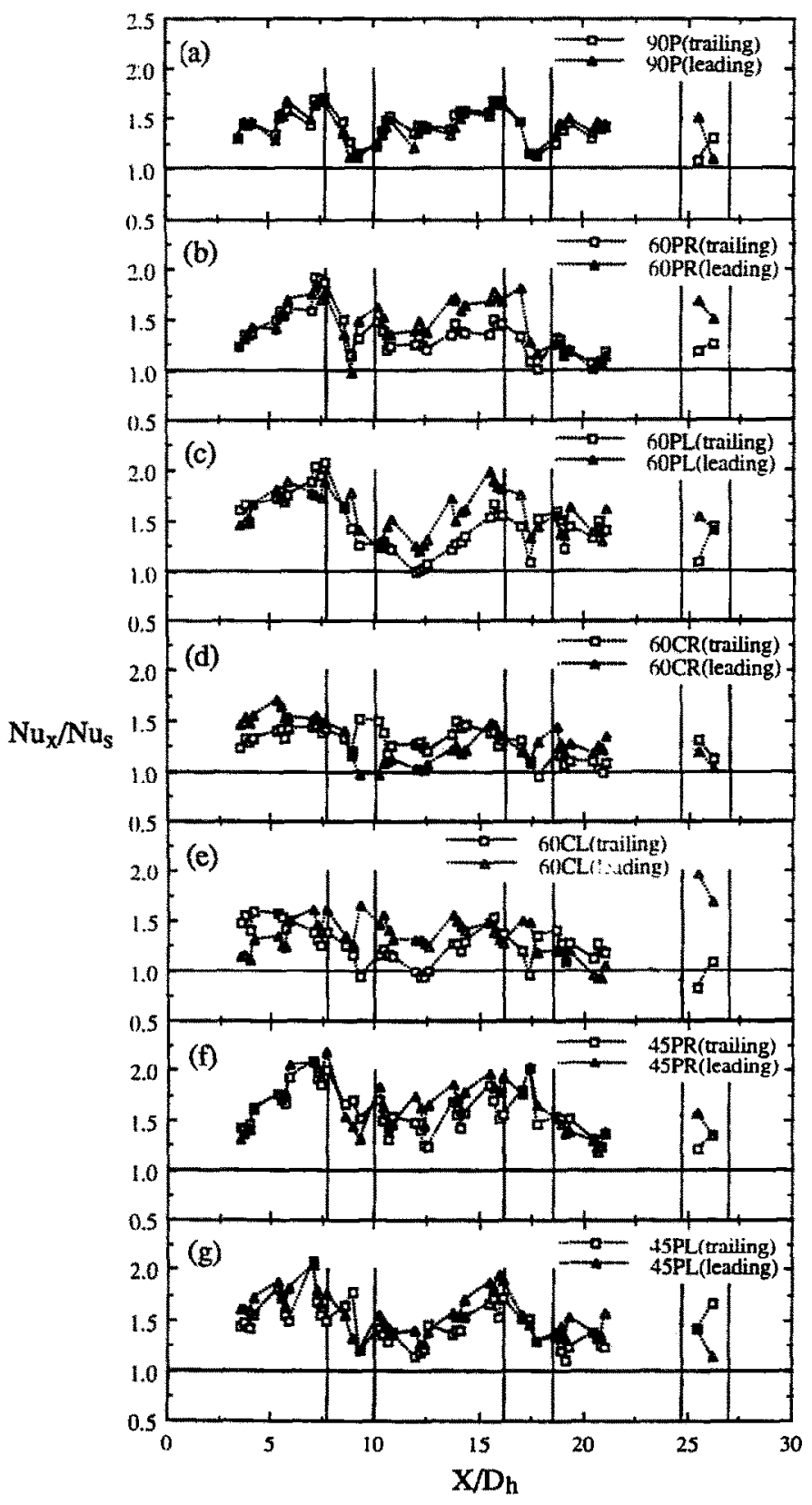

FIG. 5. Ratio of local Nusselt number of roughened passage to that of smooth passage at $R e=31300$ and $R o=0$.

$$
N u(x)=h(x) D_{h} / k
$$

Here, $h(x)$ is the local heat transfer coefficient; $q_{\mathrm{w}}$, the wall heat flux; $T_{\mathrm{w}}(X)$ and $T_{\mathrm{a}}(X)$, the local wall and air temperatures, respectively; $N u(x)$, the local Nusselt number; $x$, the streamwise distance from the inlet along the centerline; $D_{\mathrm{h}}$, the hydraulic diameter; and $k$, the thermal conductivity of air. Two methods were used to normalized experimental data to compare the present results with earlier findings and to evaluate the rotational effects on the heat transfer performance in the roughened channel. One method is to normalize by the static operating condition while the other is to normalize by a smooth duct condition for fully developed turbulent flow. A popular equation for turbulent heat transfer inside smooth passages reads [20]

$$
\begin{gathered}
N u_{\infty}=0.022 \operatorname{Pr}^{0.5} R e^{0.8} \quad \text { for } R e<10^{5} \\
N u_{\infty}=0.0185 R e^{0.8} \text { for } \operatorname{Pr}=0.707 .
\end{gathered}
$$

An uncertainty analysis of the data reduction was conducted using the method from Kline and McClin- 


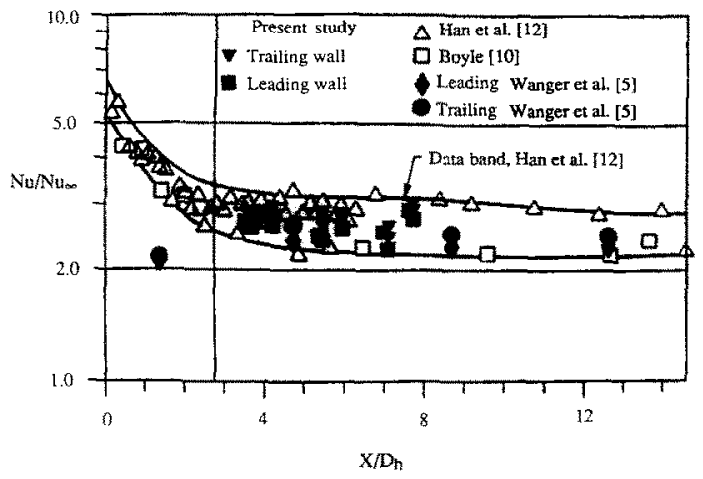

Fig. 6. Comparison of stationary heat transfer results.

tock [21]. In the present study, the resulting function is $\mathrm{Nu}$ in equation (2). Substituting the expression given in equation (1) for $h(x)$,

$$
\begin{aligned}
N u(x)=q_{\mathrm{w}} D_{\mathrm{h}} /[k \Delta T(X)] & \\
& =\left(D_{\mathrm{h}} G C_{\mathrm{p}} \Delta T_{\mathrm{a}}\right) /\left[k \Delta T(X) A_{\text {hcat }}\right] .
\end{aligned}
$$

Here, $G$ is the air mass flow rate; $\Delta T(X)=T_{\mathrm{w}}(X)-T_{\mathrm{a}}(X)$; and $A_{\text {heat }}$, the total heating area. The uncertainty in temperaturc measurements is estimated to be $\pm 1 \mathrm{C}$. The value of $T_{\mathrm{w}}(x)-T_{\mathrm{a}}(x)$ varies from 10 to $50^{\circ} \mathrm{C}$, while the difference between inlet and outlet air temperatures of the test section changes from 10 to $20^{\circ} \mathrm{C}$. The typical nondimensional
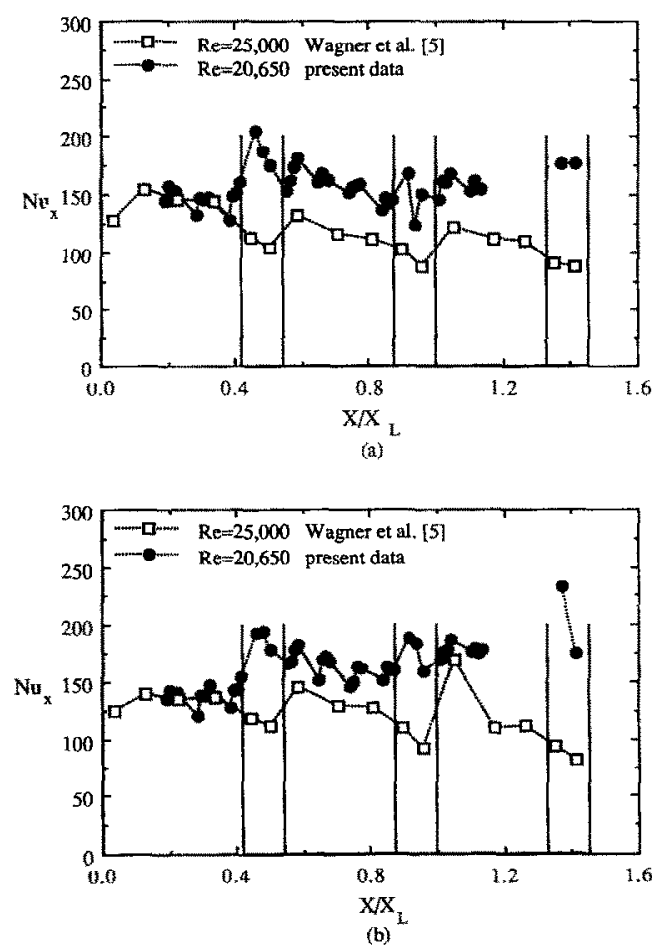

Fig. 7. Comparison of local Nusselt number distribution on the (a) trailing wall and (b) leading wall with normal ribs on the walls for stationary case. uncertainty interval for the variables in equation (5) are estimated as follows :

Specific heat of air

$C_{\mathrm{r}} \pm 0.5 \%$

Hydraulic diameter of flow passage $D_{\mathrm{h}} \quad \pm 0.5 \%$

Air flow rate

Thermal conductivity

Temperaturc

$G \quad \pm 0.5-8.0 \%$

Total heating area

$k \pm 0.5 \%$

$T \quad \pm 5.514 .5 \%$

$A_{\text {heat }} \pm 2.0 \%$.

The relative uncertainty interval for the Nusselt number is in the range of $15-25 \%$. The maximum uncertainty of the Nusselt number occurs at the lowest heat transfer coefficient on the leading wall in the rotating case. It is disclosed that the heat transfer performance under the uniform wall heat flux condition is characterized by a more uniform uncertainty over the entire flow passage than under the uniform wall temperature condition because the wall-to-air temperature difference is more uniform. All results shown in the present study are based on the averaged values of two repeated experiments for each case. The differences between the recorded wall temperatures at corresponding locations on the trailing and leading walls in stationary cases are attributed to (1) imperfect installation of thermocouples and heating foil, (2) crrors occurring in the circuit switches which were used in selecting different thermocouples to be recorded, and (3) the asymmetric inlet flow profile caused by the channel inlet geometry.

\section{RESULTS AND DISCUSSION}

\section{Stationary roughened passage}

Seven roughness configurations were employed in the present study in order to determine the effect of roughness on heat transfer performance. Results for the stationary case are presented in Figs. 4 and 5 $(R e=10240$ not shown) as the ratio of the local Nusselt number on roughened wall to that on smooth wall. The results of smooth wall cases can be found in the previous part $\mathrm{I}$ (with smooth walls). It is revealed that $45 \mathrm{PR}$ has the best overall heat transfer enhancement for the stationary case among all configurations. The cross configurations, e.g. $60 \mathrm{CL}$ and 60CR, fail to exhibit good heat transfer enhancement in comparison with other configurations. All configurations except $60 \mathrm{CR}$ have heat transfer gradually increasing along the flow in the first straight section. Case $45 \mathrm{PR}$ is highest in heat transfer enhancement. The $60 \mathrm{CR}$ unit has a better heat transfer enhancement on the leading wall in the first straight section than on the trailing wall, while the opposite is true in $60 \mathrm{CL}$. The heat transfer enhancement in the turns is generally lower than that in the straight section. In the configurations of parallel left orientation, e.g. $45 \mathrm{PL}$ and $60 \mathrm{PL}$, the extent of heat transfer enhancement is low (below 1.5) at the beginning of the second straight section but rapidly increases to a maximum in the second turn. In contrast, the configurations of parallel right orientation, e.g. 45PR and 60PR, have a fairly 


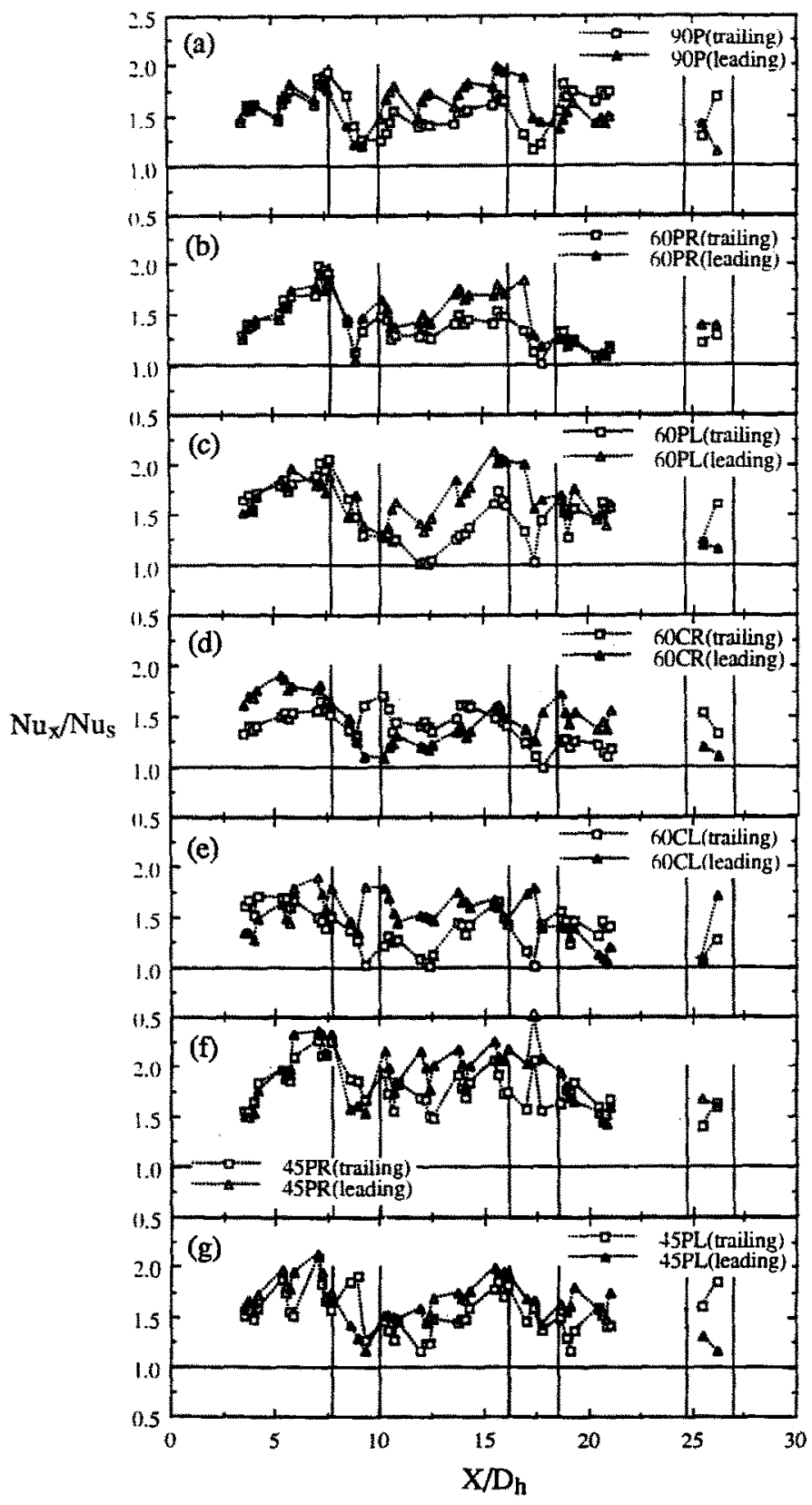

FIG. 8. Ratio of local Nusselt number of roughened passage to that of smooth passagc at $R e=10240$ and $R o=0.1389$.

uniform heat transfer enhancement in the second straight section. The trend of heat transfer enhancement in the second straight section is opposite to that in the first straight section for $60 \mathrm{CR}$ and $60 \mathrm{CL}$.

Figure 6 illustrates the distribution of the Nusselt number ratio in the first straight section for the stationary case. It shows that the present data for a flow passage with normal ribs fall within the data band of Han et al. [12]. A comparison of the local Nusselt number in a stationary passage with normal ribs is illustrated in Fig. 7. The present results coincide with Wagner et al.
[5] in the first straight section in spite of a difference in the Reynolds numbers, but are higher throughout the rest of the flow passage. There could be two main reasons for the differences: (1) the flow in the present study is developing because of no extension arm, while Wagner et al. [5] had the test section preceded by a flow-developing arm; and (2) the section lengths in the present study is shorter $\left(L / D_{\mathrm{h}}=8\right.$ for the first section, and 6.3 for the second and third sections) than that of Wagner et al. [5] (12 for the first section, and 10 for the second and third sections). It is known 


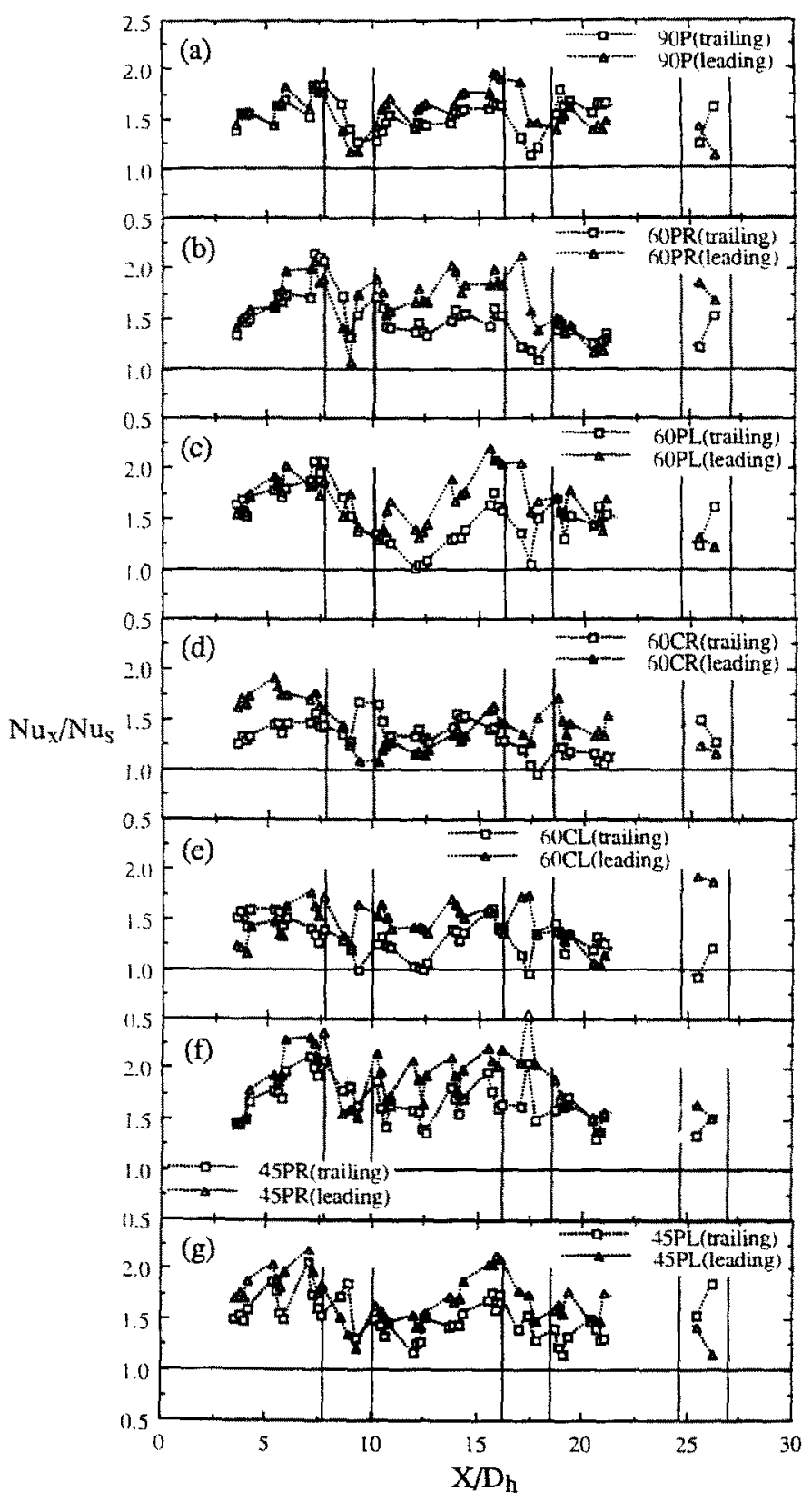

Fic. 9. Ratio of local Nusselt number of roughened passage to that of smooth passage at $R e=20650$ and $R o=0.0382$.

that flow in the turns is drastically distorted and results in high heat transfer performance. Because of the short section, the developing flow can maintain some extent of that high performance between two consecutive turns.

\section{Roughened passage in rotation}

Figures 8-11 demonstrate the ratio of the local Nusselt number for roughened walls to that for smooth walls at various Reynolds and Rossby numbers. It is revealed that in the first straight section, all configurations except $60 \mathrm{CL}$ and $60 \mathrm{CR}$ have similar heat transfer enhancement on both the trailing and leading walls. In $60 \mathrm{CR}$ heat transfer enhancement is higher on the leading wall than on the trailing wall in the first straight section, but this behavior is reversed with higher values on the trailing wall than on the leading wall at the mid-section. In contrast, $60 \mathrm{CL}$ has a higher heat transfer enhancement on the leading wall than on the trailing wall in the mid-section of the flow passage. In the second straight section, the extent of heat transfer enhancement on the leading wall is generally higher than that on the trailing wall except in case $60 \mathrm{CL}$. The reasons for the higher heat transfer 


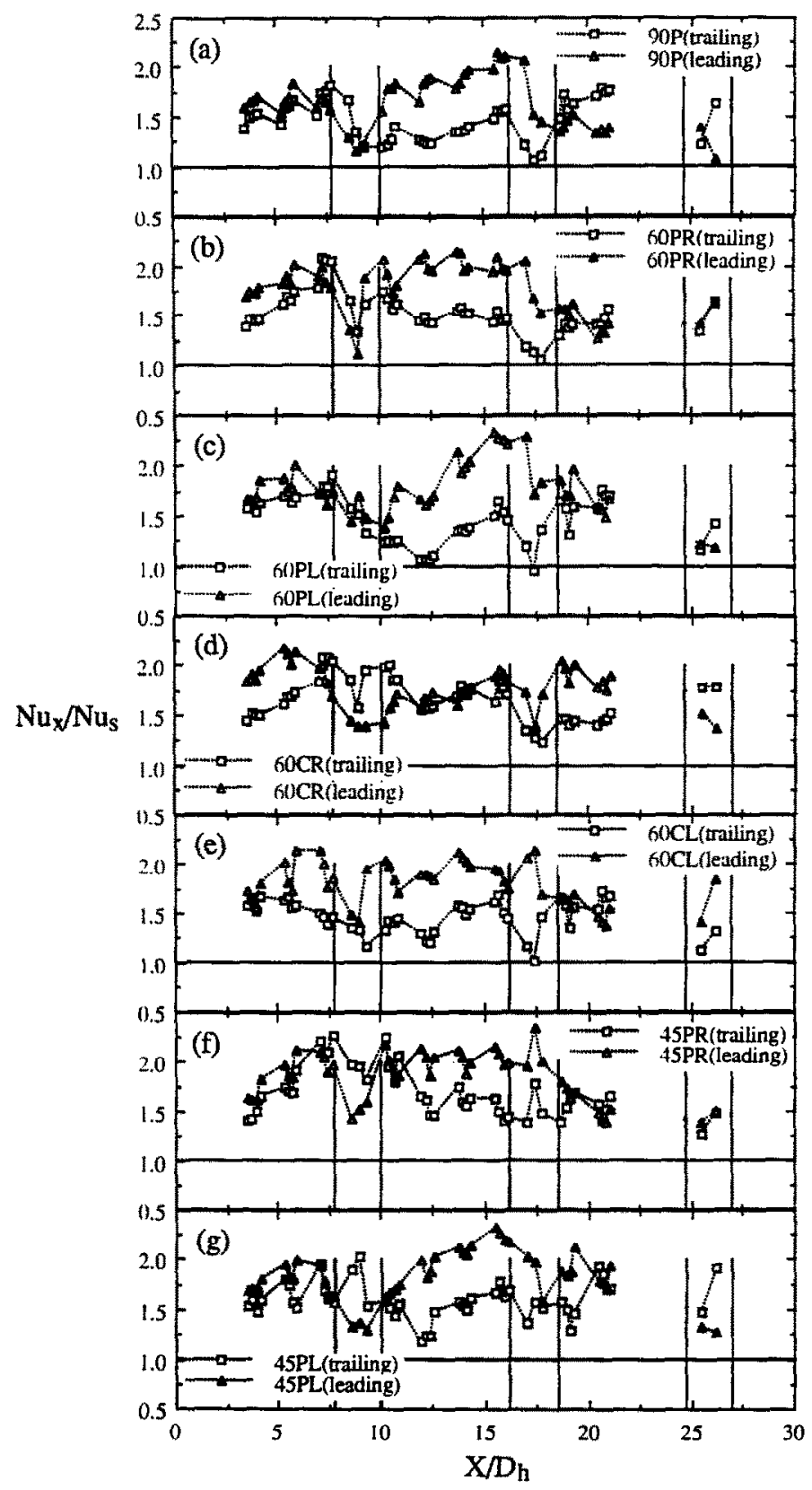

Fig. 10. Ratio of local Nusselt number of roughened passage to that of smooth passage at $R e=20650$ and $R o=0.0689$.

performance on the leading wall of the second straight section are: (1) the curvature-induced secondary fow, which reduces heat transfer on the leading wall near the first turn, is demolished as the flow enters the second straight section, and (2) the strong interaction between the turbulent flow caused by ribs and the Coriolis-induced vortex flow enhances the heat transfer from the leading wall. It is also found that the discrepancy between the enhancements on the trailing and leading walls increases with an increase of the rotational speed, which causes an increase of the enhancement on the leading wall. The extent of enhancement in the third straight section varies depending on the configurations. Heat transfer enhancement on the trailing wall at the first turn is generally higher than that on leading wall, while the opposite is true at the second turn. Over all, the configuration $45 \mathrm{PR}$ has the best heat transfer performance.

A comparison of the local Nusselt number for a flow passage with normal ribs in rotation is illustrated in Fig. 12. The present data on the trailing wall are close to Wagner et al. [5] in the first straight section in spite of different Reynolds and Rossby numbers, 


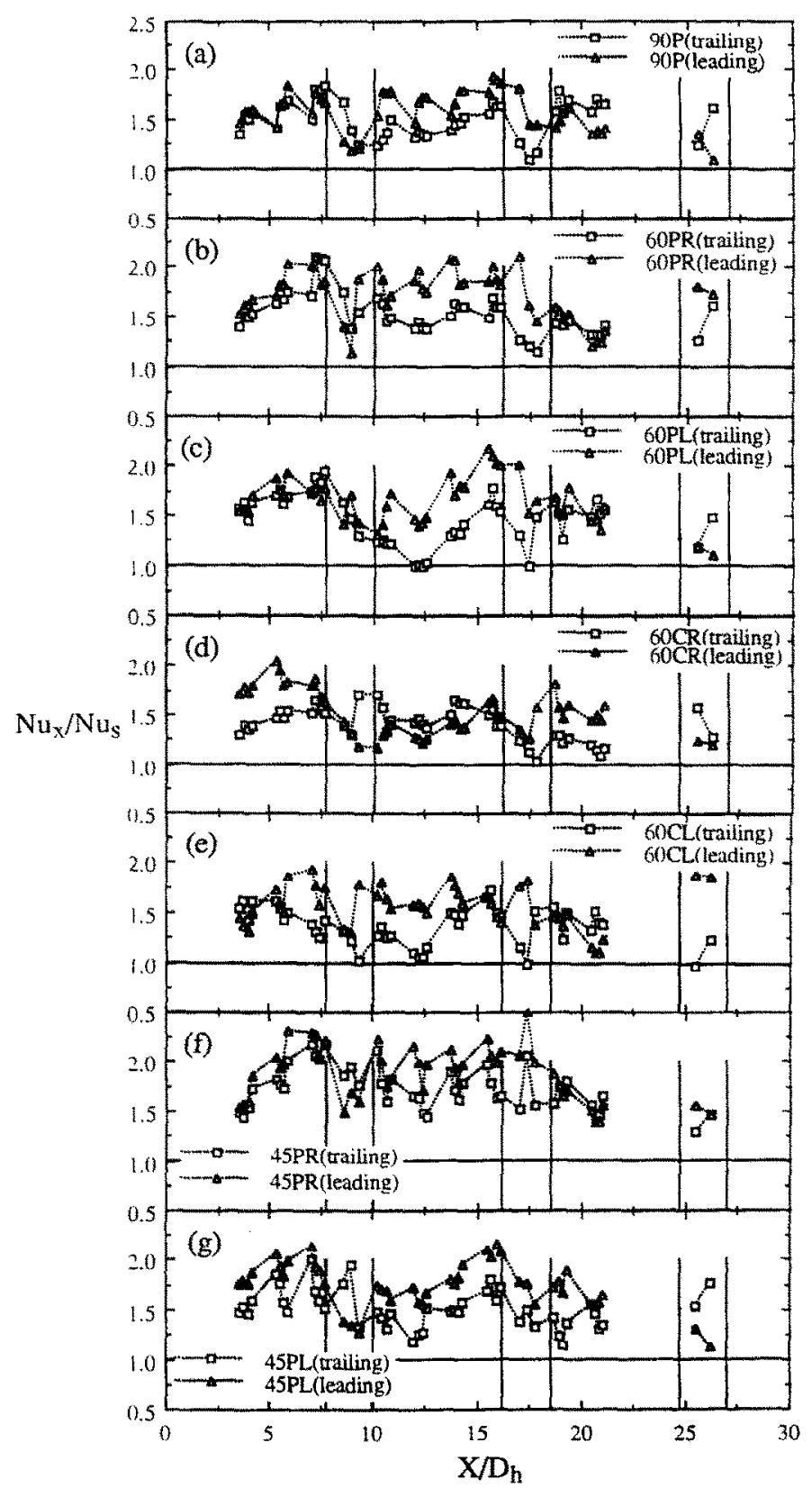

Fic. 11. Ratio of local Nusselt number of roughened passage to that of smooth passage at $R e-31300$ and $R o=0.0455$.

but subsequently become higher. The present data along the leading wall share a similar trend with Wagner et al. [5]. Figures 13(a) and (b) compare the local Nusselt number distribution in the first straight section with 45 degree ribs on the walls. For the stationary case, both results are close, but Johnson et al. [6] has a larger discrepancy between the Nusselt number on the trailing and leading walls. The small discrepancy of the present data can be attributed to the flow having no developing length (extension arm) before entering the test section.

\section{Flow mechanism in a rib-roughened passage}

Figures 14(a) and (b) plot the location of thermocouples (in solid circles) against the measured wall temperatures (in hollow circles). Several interesting phenomena are discovered from the wall temperature distribution between two consecutive ribs: the distribution between two normal ribs (with an angle-ofattack of $90^{\circ}$ ) is concave downward as shown in Fig. 14(a), while the temperature distribution between two inclined ribs (with an angle-of-attack of $45^{\circ}$ or $60^{\circ}$ ) is concave upward as seen in Fig. 14(b). Once the flow 


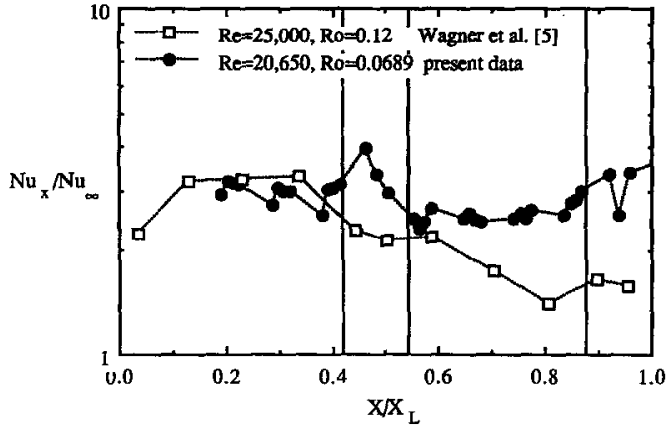

(a)

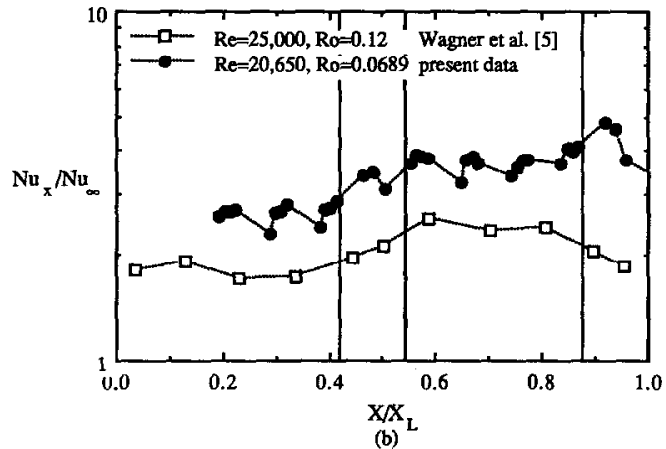

FIG. 12. Comparison of local Nusselt number distribution on the (a) trailing wall and (b) leading wall with normal ribs on the walls.

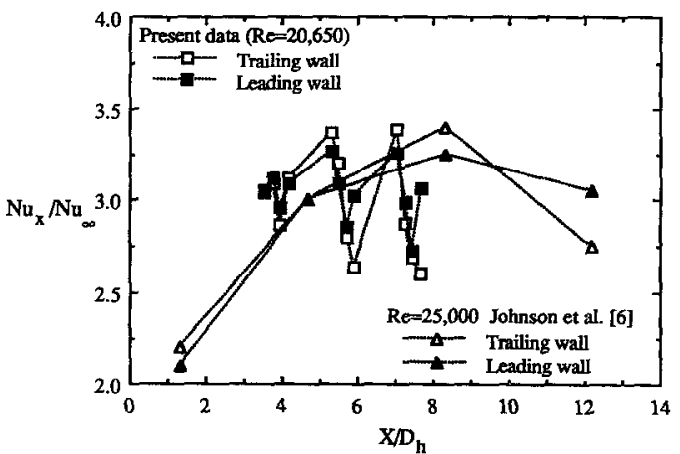

(a)

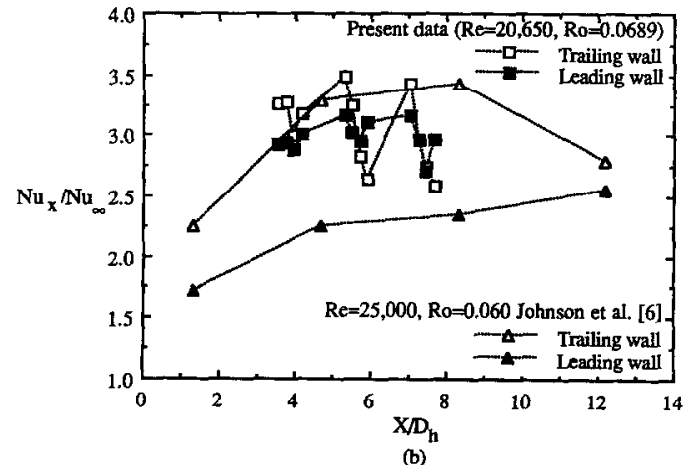

Fig. 13. Comparison of local Nusselt number distribution in the first straight section with $45 \mathrm{deg}$ ribs for (a) stationary case and (b) rotating case.

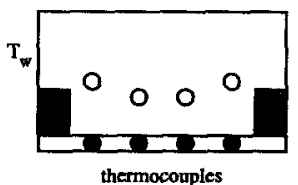

thermocouples

(a) normal ribs

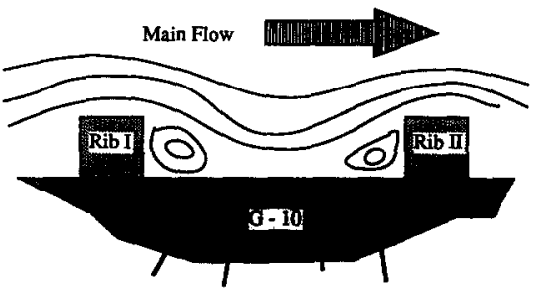

(c) normal ribs

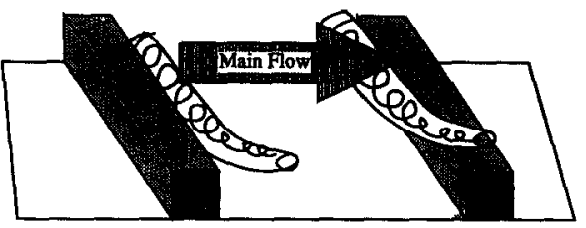

(d) inclined ribs

Fig. 14. Flow mechanism in passages with normal and inclined ribs.

encounters a rib in a flow passage with normal ribs, a pair of vortices are generated parallel to and near the rib, as shown in Fig. 14(c). The vortices located upstream from the rib II is similar to a decelerated stagnation flow with separation [22], while the other vortices located downstream from the rib I are caused by flow separation in a flow over a block (e.g. Fig. 39 in Van Dyke [23]). However, these vortices are attached to the ribs, and fluid particles in the vortices have little interaction with the main stream. As a result, the fluid temperature in the vortices, as well as the temperature near the ribs, increases under the constraint of uniform wall heat flux. In contrast, with the temperature distribution shown in Fig. 14(b), the vortices generated between two inclined ribs are not stagnant, but move along the ribs and then join the main flow, as shown in Fig. 14(d). This movement results in the vortices yielding a strong secondary flow which enhances heat transfer and thus lowers the wall temperatures near the ribs. Other phenomena found in the data are (1) the trends of temperature distribution between two consecutive ribs (both normal and inclined ribs) maintain while the system is rotating, and (2) the rotational speed affects the magnitude of the wall temperatures but has little influence on the temperature distribution trends.

\section{CONCLUSIONS}

1. Rotation improves the local heat transfer performance.

2. A significant enhancement in the heat transfer 
performance is achieved by means of rib turbulators in a serpentine passage at rest as well as in rotation.

3. In all seven configurations of roughness studied, the configuration of parallel alignment with 45 ribs of right orientation has the best overall heat transfer performance, both at rest and in rotation. The configuration of cross alignment with $45^{\circ}$ ribs of right orientation has the worst performance among the seven.

4. In general, the effect of rotation on heat transfer from ribbed walls is even on both the trailing and leading walls in the first straight section, but is better on the leading walls in the second straight section except for the case with the cross configuration. The effect of rotation in the third section is mixed depending on the configurations.

Acknowledgement-The present study was supported by the Electric Power Research Institute under the EPRI agreement RP 8006-11.

\section{REFERENCES}

I. T. J. Hajek and A. W. Higgins, Coolant passage heat transfer with rotation, NASA Contract NASA-23691, United Technologies Corporation (1984).

2. W. M. Kays and M. E. Crawford, Convective Heat and Mass Transfer. McGraw-Hill, New York (1980).

3. R. J. Clifford, Rotating heat transfer investigations on a multipass cooling geometry, $A G A R D$ Conference Proceeding No. 390: Heat Transfer and Cooling in Gas Turbine (1985).

4. J. H. Wagner, B. V. Johnson and F. C. Kopper, Heat transfer in rotating serpentine passages with smooth walls, ASME Paper No, 90-GT-331 (1990).

5. J. H. Wagner, B. V. Johnson, R. A. Graziani and F. C. Yeh, Heat transfer in rotating serpentine passages with trips normal to the flow, ASME Paper No. 91-GT-265 (1991)

6. B. V. Johnson, J. H. Wagner, G. D. Steuber and F. C. Yeh, Heat transfer in rotating serpentine passages with trips skewed to the flow, ASME Paper No. 92-GT-191 (1992).

7. Wen-Jei Yang, N. Zhang and J. Chiou, Local heat transfer in a rotating serpentine flow passage, $J$. Heat Transfer 114, 354-361 (1992)

8. S. Mochizuki, J. Takamura, S. Yamawaki and Wen-Jei
Yang. Heat transfer in serpentine flow passages with rotation, ASME Paper No. 92-GT-190 (1992).

9. W. N. Dawes, The solution-adaptive numerical simulation of the 3D viscous flow in the serpentine coolant passage of a radial inflow turbine blade, ASME Paper No. 92-GT-193 (1992).

10. R. J. Boyle, Heat transfer in serpentine passages with turbulence promoters, ASME Preprint 84-HT 24. Also issued as NASA Technical Memorandum 83614 (1984).

11. J. C. Han, Heat transfer and friction in channels with two opposite rib-roughened walls, J. Heat Transfer 106. $774.781(1984)$.

12. J. C. Han, J. S. Park and M. T. Jbrahim, Measurement of heat transfer and pressure drop in rectangular channels with turbulence promoters, NASA Contractor Report 4015 (1986).

13. P. R. Chandra, J. C. Han and S. C. Lau, Effect of rib angle on local heat/mass transfer distribution in a twopass rib-roughened channel, J. Turbomachinery 110, $233-241(1988)$.

14. J. C. Han and P. Zhang, Fffect of rih-angle orientation on local mass transfer distribution in at three-pass ribroughened channel, J. Turbomachinery 113, $123 \cdot 130$ (1991).

15. J. C. Han, P. R. Chandra and S. C. Lat, Local heat/mass transfer distributions around sharp 180 deg turns in twopass smooth and rib-roughened channels, J. Heat Transfer 110, 91-98 (1988).

16. J. C. Han and Y. M. Zhang, High performance heat transfer ducts with parallel broken and $V$-shaped broken ribs, Int. J. Heat Mass Transfer 35, 513-523 (1992).

17. N. Abuaf and D. M. Kercher, Heat transfer and turbulence in turbulated blade cooling circuit ASME Paper No. 92 GT -187 (1992).

18. Y. D. Choi, H. Iacovides and B. E. Launder. Numerical computation of turbulent flow in a a square-sectioned 180 deg bend, $J$. Fluid Engng 111, 59-68 (1989).

19. N. Zhang, J. Chiou, S. Fann and Wen-Jei Yang, Local heat transfer distribution in a rotating serpentine ribroughened flow passage, J. Heat Transfer 115, 560-567 (1993).

20. W. M. Kays and H. C. Perkins, Forced convective internal flow in ducts. In Handbook of Heat Transfer Fundamentals (Edited by W. M. Rohsenow. J. P. Hartnet and E. N. Ganic), pp. 7-28. McGraw-Hill, New York (1985).

21. S. J. Kline and F. A. Mcclintock, Describing uncertainties in single sample experiments, Mech. Engng 75, 3-8 (1953).

22. H. Schlichting, Boundary Layer Theory. McGraw-Hill, New York (1979).

23. M. Van Dyke, An Album of Fluid Motion. The Parabolic Press, Standford (1982) 